\title{
O Desenvolvimento do Raciocínio Lógico através de Objetos de Aprendizagem
}

\author{
Angélica Taschetto Scolari, Giliane Bernardi \\ Centro Universitário Franciscano - UNIFRA, Santa Maria - RS \\ angelicascolari@gmail.com,giliane@unifra.br \\ Andre Zanki Cordenonsi \\ Universidade Federal de Santa Maria - UFSM, Santa Maria - RS \\ andrezc@inf.ufsm.br
}

\begin{abstract}
Resumo. O desenvolvimento do raciocínio lógico nos alunos é uma necessidade para fazê-los pensar de forma mais crítica acerca dos conteúdos das diferentes disciplinas, tornando-os mais argumentativos com base em critérios e em princípios logicamente validados. Este trabalho tem como objetivo principal apresentar o desenvolvimento de objetos de aprendizagem para o auxílio no desenvolvimento do raciocínio lógico. Serão apresentados quatro objetos de aprendizagem que foram modelados e desenvolvidos segundo as normas de padronização estabelecidas pelo projeto RIVED para Objetos de Aprendizagem.
\end{abstract}

Palavras-Chave: Ensino de Lógica, Raciocínio Lógico, Objetos de Aprendizagem, RIVED, Agente Pedagógicos

\section{Logic Reasoning Development Through Learning Objects}

Abstract: The logic reasoning development in students is an import goal to improve the critical thinking in different subjects. The students can use more important arguments if they use principles and criteria logically validated. The main goal of this paper is presents the learning objects development to aid students and teachers to improve their logical reasoning. Four objects were been modeled and development, using the stand the established by RIVED project of Learning Objects.

Keywords: Logic Teaching, Logic Reasoning, Learning Objects, RIVED, Pedagogical Agents. 


\section{Introdução}

Com o avanço das Tecnologias da Informação e da Comunicação (TIC), houve uma crescente aceleração no desenvolvimento do processo de ensino e aprendizagem do aluno. Porém, muitos ainda possuem dificuldade em compreender e raciocinar sobre o que está sendo proposto em um determinado problema, notando-se uma grande dificuldade dos mesmos com relação ao raciocínio lógico. Observa-se que o ensino da lógica geralmente é tratado nas primeiras fases da aprendizagem, onde os alunos devem aprender a desenvolver o raciocínio lógico para auxiliar na resolução de problemas.

Para (Rauber et al., 2003) existem três habilidades básicas que devem ser adquiridas pelo estudante no processo de alfabetização: aprender a ler, aprender a escrever e aprender a resolver problemas matemáticos. Porém, para os autores estes aspectos deveriam passar para um nível mais avançado relacionado a "aprender a ler bem, aprender a escrever bem e aprender a resolver problemas matemáticos bem”, que podem ser alcançados através do desenvolvimento do raciocínio lógico.

Tecnologias interativas, como multimídia, possuem grande potencial para aplicações na área educacional, oportunizando mudanças em relação a situações de aprendizagem. Neste contexto, objetos de aprendizagem se apresentam como um meio facilitador da aprendizagem, para assim auxiliar os professores no em suas atividades pedagógicas, tanto em sala de aula, como além dela.

O objetivo principal deste trabalho é apresentar o desenvolvimento de Objetos de Aprendizagem para servir de apoio ao exercício do raciocínio lógico. Através destes objetos pretende-se proporcionar uma forma de estimular os alunos a praticar e exercitar o desenvolvimento da lógica desde a infância, através de atividades simples e dinâmicas.

Os objetos foram modelados a partir das normas de padronização sugeridas no Projeto RIVED - Rede Interativa Virtual de Educação, no qual os objetos de aprendizagem apresentados são modelados e desenvolvidos de acordo com etapas específicas. Os objetos de aprendizagem estão sendo desenvolvidos em Flash, usando tecnologias interativas, que possuem grande potencial para aplicações na área educacional.

\section{O Ensino-Aprendizagem de Lógica}

A aprendizagem da lógica faz com que o pensamento proceda corretamente a fim de chegar a conhecimentos verdadeiros. Segundo (Copi, 1978), "O estudo da Lógica é o estudo dos métodos e princípios usados para distinguir o raciocínio correto do incorreto".

Assim, pode-se afirmar que a lógica trata do estudo do raciocínio, ou seja, sistemas que definem como pensar de forma mais crítica no que diz respeito a opiniões, inferências e argumentos, dando sentido ao pensamento. Para (Abar, 2006), o aprendizado da lógica auxilia os estudantes no raciocínio, na compreensão de conceitos básicos, na verificação formal de programas e melhor os prepara para o entendimento do conteúdo de tópicos mais avançados.

Para Piaget (Piaget, 1975), o conhecimento evolui progressivamente, por meio de estruturas de raciocínio que substituem umas às outras, através de estágios. Isto significa que a lógica e as formas de pensar de uma criança são completamente diferentes da lógica dos adultos. Em sua Teoria, Piaget identifica os estágios de desenvolvimento da criança, sendo que para o autor, é no estágio operatório formal que a criança começa a desenvolver seu pensamento como o de um adulto, assim podendo 
desenvolver idéias abstratas e iniciar seu raciocínio lógico. Por isto, o incentivo ao desenvolvimento do raciocínio lógico é muito importante neste estágio, que é desenvolvido entre os 12 e 15 anos de idade.

As conseqüências do desenvolvimento não eficaz desta “capacidade” refletem-se futuramente, quando os estudantes passam a se deparar com níveis cada vez mais elevados de situações em que precisam agir de forma lógica e organizada. Segundo (Rauber et al., 2003), é comum encontrar alunos universitários com dificuldades para interpretar o que estão lendo, por não terem sido alfabetizados para entender o que está "por trás" daquilo que está escrito, ou seja, o real significado e contexto.

As dificuldades podem surgir ao interpretar um texto, ou até mesmo no momento de se expressar de forma lógica. Muitas pessoas possuem dificuldades em expressar suas idéias de forma lógica e organizada. Desta forma, mesmo tendo grandes idéias, se não conseguirem validar de forma clara suas convicções não conseguirão sustentar as mesmas.

Da mesma forma que na leitura ou escrita, o raciocínio lógico na resolução de problemas matemáticos é um fator de extrema importância. É fundamental que os alunos compreendam e raciocinem sobre o que está sendo proposto e não somente decorem e apliquem fórmulas.

Diante de todas estas dificuldades é necessário que o raciocínio lógico seja desenvolvido desde as primeiras etapas, sendo que a Informática, através de jogos educacionais, pode contribuir de forma motivadora para isto.

Para (Weis et al., 2001) “...existem crianças com baixo rendimento escolar que, diante do computador, mostram-se mais participativas e interessadas”. Para tanto, é de fundamental importância a inserção da informática nas escolas, sendo que o computador pode influenciar no aprendizado da criança. Constata-se que o desenvolvimento de atividades informatizadas para a aprendizagem de lógica pode auxiliar o aluno em seu raciocínio lógico. Também se pode citar o ensino a distância, que vem apresentando um grande crescimento na área da educação, servindo como apoio pedagógico para o aprendizado do aluno. Objetos de aprendizagem podem ser citados como exemplos de abordagens a serem utilizadas como apoio ao ensino-aprendizagem, tanto para uso em sala de aula como para prática à distância, sem a presença do professor.

\section{Objetos de Aprendizagem}

Com o avanço das Tecnologias da Informação e da Comunicação (TICs) houve uma crescente aceleração no desenvolvimento no processo de ensino e aprendizagem e na elaboração de materiais didáticos, fazendo uso do som, cor e movimento, propiciando uma maior interatividade com os usuários.

Os objetos produzidos, também chamados Objetos de Aprendizagem, podem ser facilmente utilizados pelos professores, sendo facilmente configuráveis e adaptados para suas necessidades particulares. Um Objeto de Aprendizagem é definido, segundo o Comitê de Padronização das Tecnologias de Aprendizagem (LTSC), como "qualquer entidade digital ou não digital, que pode ser utilizada, reutilizada ou referenciada durante o aprendizado apoiado pela tecnologia” (IEEE, 2002).

(Tarouco, 2004) entende que objetos de aprendizagem "são recursos digitais usados para apoiar a aprendizagem”. Esta mesma autora cita como exemplo de objetos de aprendizagem as simulações, as calculadoras eletrônicas, as animações, os tutoriais, os textos, os sites www, os clips de áudio e vídeo, as ilustrações, os diagramas, os mapas, entre outros. 
Um dos fatores importantes na utilização de um objeto de aprendizagem é tornálo uma ferramenta de apoio às práticas pedagógicas, capaz de ajudar o professor a reter a atenção dos alunos e ao mesmo tempo torná-lo um meio facilitador da aprendizagem, estimulando visualmente os alunos através das animações, cores e movimentos.

Conforme (Nunes, 2004), outro fator importante a destacar é que o professor, quando faz uso dos objetos de aprendizagem pode planejar suas aulas fazendo uso deles, conseguindo maior flexibilidade para se adaptar ao ritmo e ao interesse dos alunos, mantendo seus objetivos de ensino.

Uma das vantagens em utilizar objetos de aprendizagem no aprendizado dos alunos é que estes propiciam a curiosidade para resolver problemas, ampliam conhecimentos e despertam interesses. Segundo (Nunes, 2004), “a vantagem dos objetos de aprendizagem é que, quando bem escolhidos, podem ajudar em cada uma dessas fases. Existem objetos de aprendizagem muito bons para motivar ou contextualizar um novo assunto a ser tratado, outros ótimos para visualizar conceitos complexos, alguns que induzem o aluno a certos pensamentos, outros ideais para uma aplicação inteligente do que estão aprendendo...”.

Para complementar, cita-se (Galotta, 2007), que afirma que os objetos de aprendizagem permitem a construção de contextos digitais para os conteúdos que serão explorados. Esses contextos fazem uso de uma série de ferramentas midiáticas, tais como música, desenhos, gráficos, simulações, jogos etc. A contextualização permite aos alunos traçar mais facilmente uma relação entre determinado conteúdo e suas aplicações práticas e enxergar a interdependência das várias disciplinas.

O uso das TIC, como um meio facilitador da aprendizagem, vem contribuir, apoiar e auxiliar os professores no seu fazer pedagógico, cabendo ao mesmo extrair e aproveitar as potencialidades que os objetos de aprendizagem oferecem. Dessa forma, (Galotta, 2007) aponta que os objetos de aprendizagem não devem ter a pretensão de substituir o professor nem de tornar o aluno um autodidata em relação a um determinado conteúdo. Devem ser vistos como ferramentas de apoio ao ensino de conteúdos e para permitir uma comunicação mais direta entre aluno e professor.

A partir deste estudo, identificou-se uma iniciativa considerada das mais relevantes, que envolve o desenvolvimento de objetos de aprendizagem através de normas e procedimentos, que é o Projeto Rede Interativa Virtual de Educação, mais conhecido como RIVED. O projeto tem como objetivo a produção de conteúdos pedagógicos digitais, na forma de objetos de aprendizagem. Estes conteúdos visam, segundo o projeto, estimular o raciocínio e o pensamento de estudantes. A próxima seção detalha o funcionamento do projeto RIVED, de forma a conhecer seu procedimento de modelagem e desenvolvimento de objetos de aprendizagem.

\subsection{O projeto RIVED}

O Projeto RIVED (Rived, 2007) é um programa da Secretaria de Educação a Distância - SEED, que tem como foco principal o desenvolvimento de animações e simulações. Este projeto iniciou no ano de 1997, através de um acordo realizado entre o Brasil e os Estados Unidos, para o desenvolvimento da tecnologia para uso pedagógico. Logo após, o Brasil iniciou sua participação no projeto, realizando uma parceria entre a Secretaria de Ensino Médio e Tecnológica (hoje SEB - Secretaria de Educação Básica) e a Secretaria de Educação a Distância (SEED). Peru e Venezuela também tiveram participação no projeto onde, até o ano de 2003, a equipe do RIVED, na SEED, foi responsável pela produção de vários objetos de aprendizagem para o Ensino Médio. A partir de 2004, a SEED transferiu o projeto para Universidades, onde recebeu o nome de Fábrica Virtual. 
Assim, expandiu-se a produção de conteúdos para o Ensino Fundamental, Profissionalizante e para atendimentos especiais. Através desta mudança, o RIVED Rede Internacional Virtual de Educação passou a se chamar RIVED - Rede Interativa Virtual de Educação.

Os objetos de aprendizagem do projeto RIVED são baseados em atividades multimídia, que servem como instrumentos para despertar novas idéias, relacionar conceitos, despertar a curiosidade e resolver problemas. Estas atividades estão disponíveis na forma de animações e simulações que visam despertar o raciocínio na aprendizagem do aluno.

O projeto, além de disponibilizar conteúdos digitais e contribuir para o melhoramento das disciplinas curriculares, realiza capacitações de professores sobre a metodologia para produzir e utilizar os objetos de aprendizagem nas instituições de ensino superior e na rede pública de ensino.

O professor tem liberdade de usar os conteúdos que são disponibilizados pelo RIVED através de um mecanismo de busca, que permite visualizar, copiar e comentar os conteúdos publicados, desde que atribuam o crédito aos autores. Cada objeto de aprendizagem vem acompanhado de um guia do professor com sugestões de uso.

Para a modelagem e desenvolvimento dos objetos propostos neste artigo, estão sendo utilizadas as normas de padronização sugeridas no Projeto RIVED, que especifica etapas para o desenvolvimento de um objeto de aprendizagem, desde sua concepção até a implementação. Algumas destas etapas podem ser destacadas:

- Desenvolvimento do Design Pedagógico: detalhamento dos objetivos educacionais do objeto proposto;

- Desenvolvimento do Roteiro do Objeto: detalhamento de cada tela de navegação do objeto;

- Desenvolvimento do Guia do Professor: roteiro para que o professor utilize o objeto de aprendizagem, contendo questões como objetivo, pré-requisitos para utilização do objeto, tempo de duração da atividade, entre outras;

- Definição do Padrão Visual: o projeto apresenta uma proposta de padronização de elementos gráficos, cores, nomeação de arquivos, entre outros.

\section{Os Objetos Desenvolvidos}

Os Objetos de Aprendizagens apresentados neste trabalho estão sendo desenvolvidos com o intuito de auxiliar no desenvolvimento do raciocínio lógico de forma criativa e motivadora.

Logo após o uso do objeto de aprendizagem de lógica, espera-se que o aluno possa apresentar um melhor desempenho ao interpretar um exercício ou problema, para que os mesmos sejam resolvidos com maior facilidade.

Foram selecionados exercícios de lógica retirados do livro "Que tal um pouco de lógica?!” (Rauber et al., 2003), sendo que no mesmo são apresentados vários tipos de atividades, mostrando como aprender a definir de forma lógica. Os autores descrevem a importância do tema e da obra da seguinte forma: “...essa obra pretende ser um instrumento que auxilie os alunos a terem um acesso ao raciocínio lógico de uma forma bastante simples e dinâmica, por meio de histórias, charadas e exercícios. Visa contribuir para um pensar mais crítico e cuidadoso no que diz respeito a opiniões, inferências e argumentos. Pensar e argumentar logicamente é indispensável para dar sentido ao pensamento."

Diversas atividades foram selecionadas e transformadas em objetos de aprendizagem, sendo que este artigo apresenta quatro destas atividades, que são: "Distribuindo Maçãs”, 
“A Distribuição das Moedas”, “A Travessia do Viajante” e “Troca dos Sapos”. Os objetos foram modelados de acordo com as normas do Projeto RIVED.

Para (Abreu et al., 2006), a construção de um objeto de aprendizagem envolve três etapas distintas: planejamento (modelagem), desenvolvimento e validação. A documentação da etapa de planejamento dos objetos foi realizada de acordo com as normas do projeto RIVED, descritas anteriormente. As mesmas não serão apresentadas neste artigo.

Para acompanhar o aluno durante a execução das atividades, foi inserido em todas as interfaces um agente pedagógico na forma de um computador animado. $\mathrm{O}$ mesmo faz parte da biblioteca de agentes Microsoft Agent e tem como objetivo servir como companheiro do aluno na realização das atividades, $\mathrm{O}$ agente irá interagir com o aluno na forma de questionamentos, opiniões, diálogos motivacionais, fornecendo dicas sobre a atividade em questão, além de apresentar curiosidades acerca do tema "Lógica". Para Hayes-Roth apud (Reategui et al., 2006), a concepção do agente deve ser definida de acordo com alguns requisitos considerados essenciais a um agente pedagógico, que são:

- Individualidade: expressa por sua identidade, história de vida e aparência;

- Aspectos Conversacionais: expressos pelo conteúdo da fala, maneira de falar, e maneira de gesticular;

- Empatia: expressa através da dinâmica emocional;

- Aspectos Sociais: expressos através dos padrões de interação social;

- Inteligência: expressa através do papel e dinâmica do papel do agente dentro da aplicação.

A figura 01 apresenta a interface inicial do ambiente, onde o agente apresenta-se para o aluno, explicitando seu objetivo.

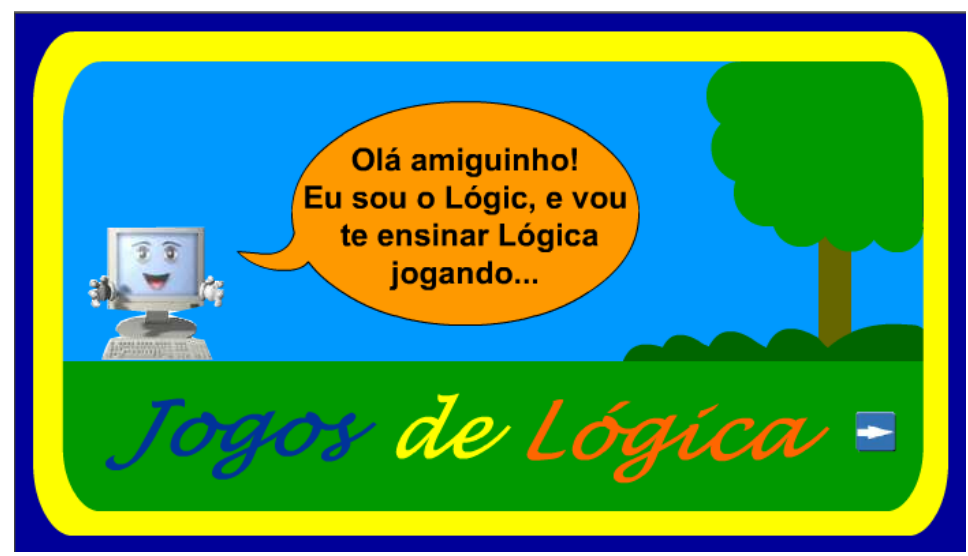

Figura 01. Interface de Abertura com o Agente Pedagógico

A figura 2 apresenta a interface principal do ambiente, que permite o acesso aos objetos de aprendizagem desenvolvidos. As próximas seções apresentam o desenvolvimento dos quatro objetos citados. 


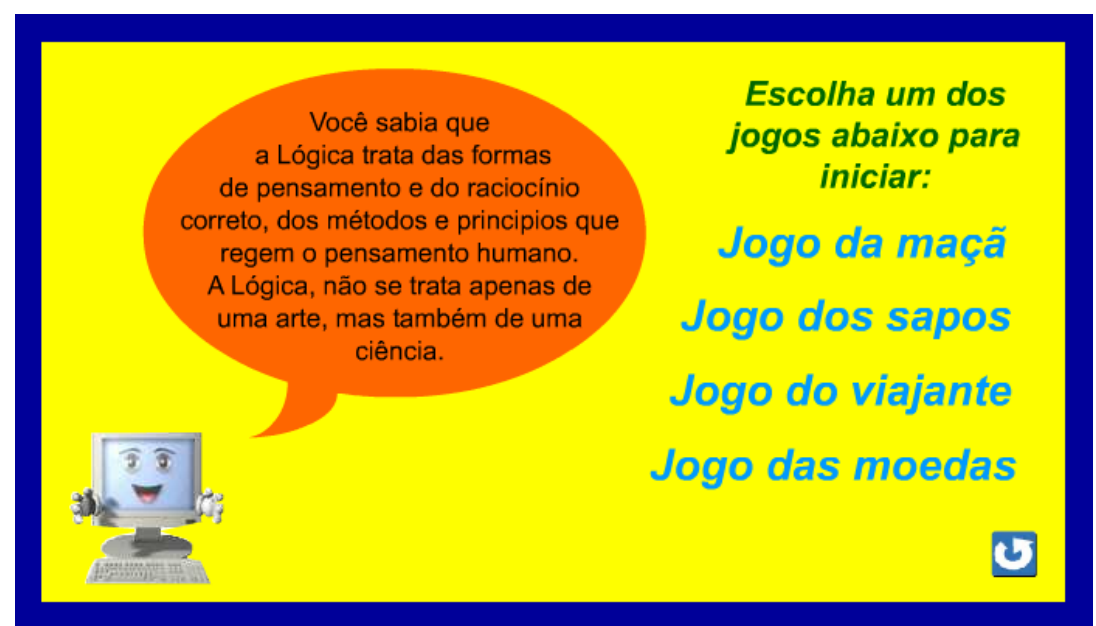

Figura 2. Interface Principal de Acesso aos Objetos de Aprendizagem

\subsection{Objeto de Aprendizagem "Distribuindo Maçãs”}

A atividade "Distribuindo maçãs" faz com que o aluno aprenda a definir de forma lógica. O objetivo da atividade é distribuir uma maçã para cada criança, sendo que é necessário que reste uma maçã na cesta. Todas as crianças devem receber maçãs inteiras. $\mathrm{O}$ aluno deverá pensar nas diversas possibilidades para realizar a distribuição, usando sua imaginação. A figura 3 apresenta a interface do jogo descrito.

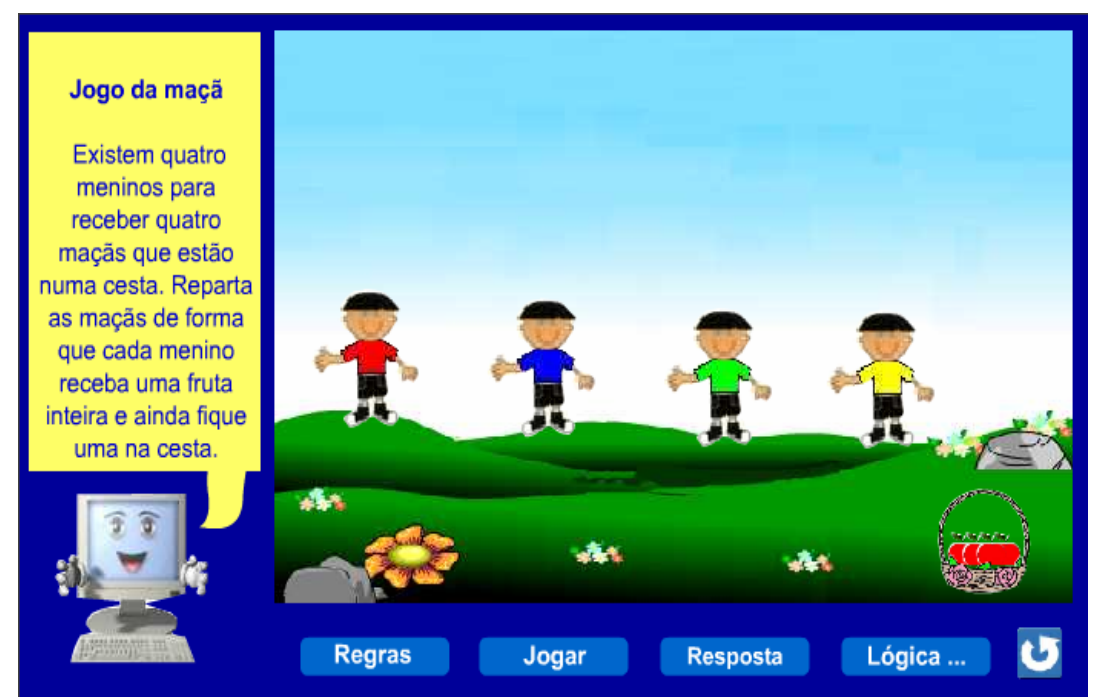

Figura 3. Interface do objeto de aprendizagem "Distribuindo maçãs"

Ao iniciar a atividade, o aluno irá visualizar uma interface com quatro crianças a espera de receber maçãs. Junto às crianças encontra-se uma cesta com quatro maçãs inteiras dentro. $\mathrm{O}$ aluno terá que distribuir as maçãs para as crianças, de modo que cada criança receba uma fruta inteira e ainda fique uma dentro da cesta. Para a distribuição será necessário clicar com o mouse sobre a maçã e arrastar em direção a criança. O aluno poderá movimentar as maçãs e a cesta quantas vezes for necessário, até encontrar uma solução. Assim que a distribuição estiver correta, aparecerá uma mensagem na tela, informando o aluno que seu raciocínio está correto. Na mesma interface o aluno poderá buscar informações sobre lógica, para assim ampliar seu conhecimento. 


\subsection{Objeto de Aprendizagem “A Distribuição das Moedas”}

Para a atividade das "moedas", o aluno deve encontrar uma disposição para as mesmas que satisfaça as restrições estabelecidas pelo jogo. A interface principal é formada por uma matriz com 45 posições (09 X 05), onde 09 moedas estão dispostas na última linha.

O aluno pode modificar a posição das moedas livremente, até que atinja seu objetivo: distribuir as moedas de modo que formem 08 seqüências (horizontal, vertical ou diagonal), contendo três moedas em cada. A figura 4 apresenta a solução da atividade.

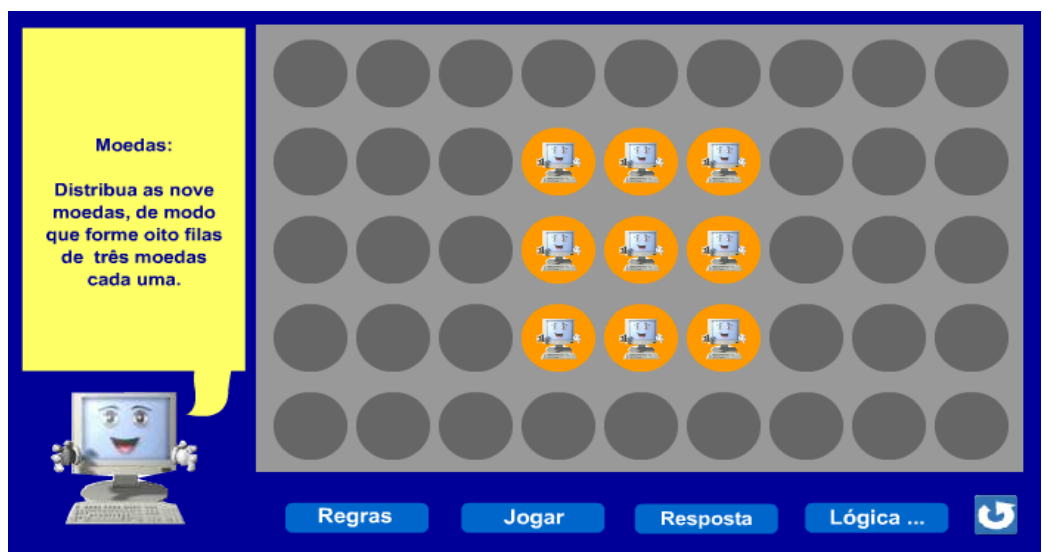

Figura 4. Interface do objeto de aprendizagem “A Distribuição das Moedas”

\subsection{Objeto de Aprendizagem "A Travessia do Viajante"}

Na atividade “A Travessia do Viajante” o aluno deverá fazer com que um viajante consiga levar um milho, uma galinha e uma raposa de um lado do rio para o outro. Ele deverá ter um certo cuidado, pois raposas comem galinhas e galinhas adoram milho, e sabe-se que raposas não gostam de milho. Caso ele deixe a galinha sozinha de um lado do rio com o milho, a galinha comerá o milho; caso ele deixe a raposa sozinha com a galinha, a raposa comerá a galinha; já a raposa não gosta de milho, assim os dois poderão ficar sozinhos. Na figura 5 é apresentada a interface do jogo.

Nesta interface, o aluno visualizará a imagem de um rio, onde em uma das margens esta posicionado um barco com o viajante dentro. Os seus pertences (raposa, galinha e milho) estão na beira do rio, sendo que o aluno deve clicar com o mouse sobre os mesmos para poder colocá-los dentro do barco.

O objetivo é fazer com que o aluno consiga levar todos os pertences do viajante para o outro lado do rio. O viajante poderá fazer várias viagens, mas só poderá levar um pertence de cada vez. Para a movimentação do barco é só clicar nas setas, posicionadas na beira do rio.

\subsection{Objeto de Aprendizagem "Troca dos Sapos”}

Na atividade de Troca dos Sapos, o aluno deve usar seu raciocínio para conseguir atravessar os sapos de um lado para o outro da tela. $\mathrm{Na}$ interface desenvolvida, existem cinco pedras na lagoa, com dois sapos verdes do lado esquerdo e dois sapos amarelos do lado direito. A pedra do meio permanece, inicialmente, desocupada e, deste modo, disponível para as trocas de posição. 


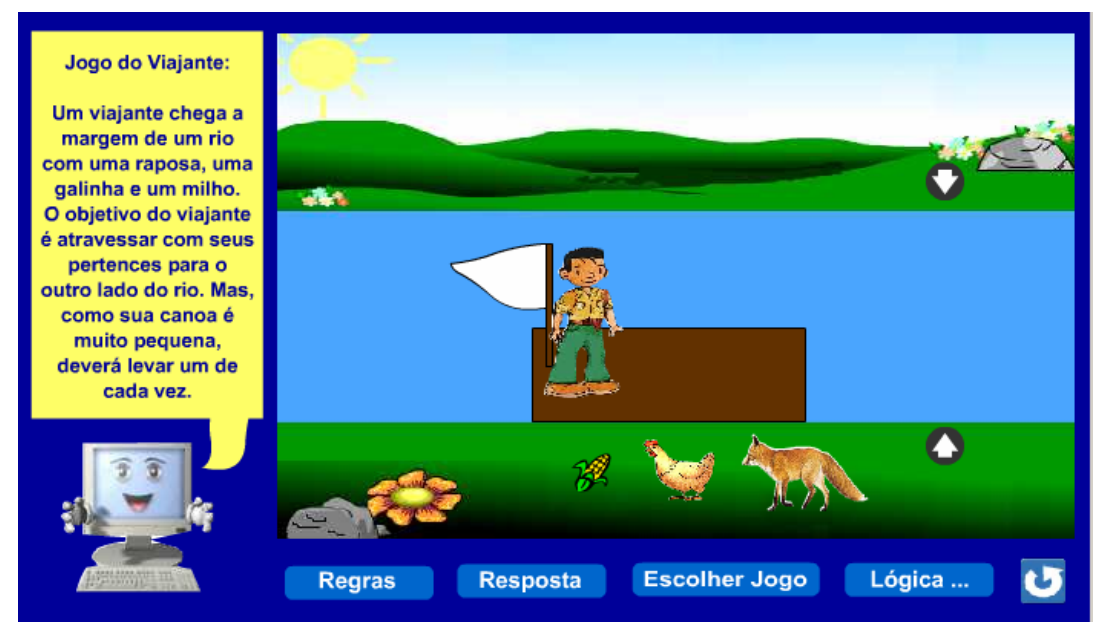

Figura 5. Interface do objeto de aprendizagem “A Travessia do Viajante”

O aluno deverá pensar nas diversas possibilidades de passar os sapos de um lado para o outro através de regras específicas. A figura 6 apresenta a posição inicial do jogo. As regras do jogo são as seguintes: os sapos verdes (posicionados à esquerda), devem ser deslocados até as duas pedras mais à direita, enquanto que os sapos amarelos (posicionados à direita), devem ser deslocados até as duas pedras mais à esquerda. Além disso, os sapos verdes só podem se deslocar para a direita e os amarelos para a esquerda. A locomoção de um sapo só ocorre em duas situações: se há um espaço (pedra) vazio na posição imediatamente adjacente a sua, na direção em que ele pode se deslocar; ou se há um sapo de cor diferente na posição imediatamente adjacente a sua e um espaço vazio logo depois, ambos na posição em que ele é permitido se deslocar. Só é permitido pular um sapo de cada vez.

Desta forma, quando o aluno clica com o mouse em um sapo, o objeto só realiza o movimento se ele for possível. Caso o sapo não possa ser movimentado por infringir alguma regra, o mesmo não se deslocará. A interface possui um botão Resposta que pode ser utilizado pelo aluno se ele não encontrar a resposta para o exercício. Neste caso, os passos necessários para completar o jogo são apresentados.

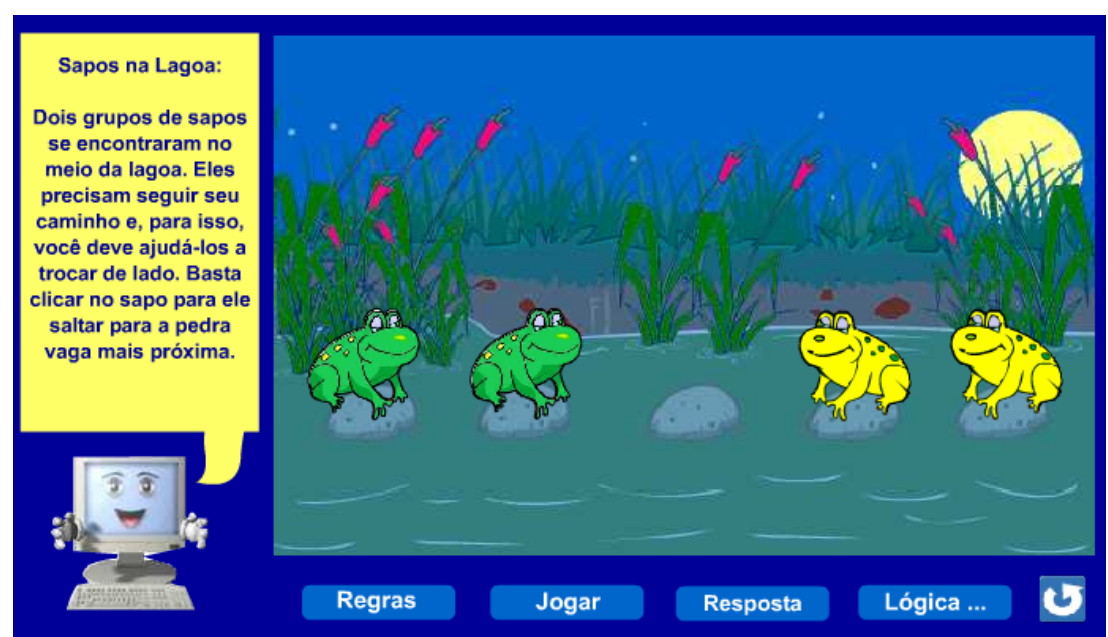

Figura 6. Interface do Objeto de Aprendizagem “Troca dos Sapos” 


\section{CONSIDERAÇÕES FINAIS}

A importância da Informática nas escolas vem se destacando devido as crianças mostrarem-se mais participativas diante do computador. Os Objetos de Aprendizagem propostos neste trabalho foram desenvolvidos com o intuito de auxiliar no processo de aprendizagem dos alunos, procurando despertar o raciocínio lógico dos mesmos. Assim, ao finalizar a construção do Objeto de Aprendizagem para o Ensino e Aprendizagem de Lógica, espera-se que o aluno possa apresentar um melhor desempenho ao interpretar um exercício ou problema, para que os mesmos sejam resolvidos com maior facilidade. Para o desenvolvimento dos Objetos de Aprendizagem foram de fundamental importância as orientações da Rede Interativa Virtual de Educação - RIVED, que auxiliaram no processo de planejamento e desenvolvimento dos objetos apresentados.

Na etapa atual de desenvolvimento está sendo finalizada a especificação do agente pedagógico Lógic. Como trabalhos futuros, pretende-se implementar as funcionalidades do Agente para que o mesmo possa interagir de forma mais inteligente e criativa com o usuário que estará utilizando o ambiente.

Ainda, pretende-se desenvolver o Guia do professor para que os objetos desenvolvidos possam efetivamente ser utilizados com todo seu potencial. Por fim, será realizada a validação dos objetos desenvolvidos, concluindo as etapas de construção dos objetos de aprendizagem.

\section{REFERÊNCIAS}

Abar, C. 2006. Noções de Lógica Matemática. Disponível em: www.pucsp.br/ logica/

Abreu, Marlon F.; Cordeiro, Rogério A.; Rapkiewicz, Clevi E.; Canela, Maria C. 2006. Utilizando Objetos de Aprendizagem no Processo de Ensino e Aprendizagem de Química no Ensino Médio: o Caso dos Óxidos e da Poluição Atmosférica. Anais do XXVI Congresso da SBC. WIE I XII Workshop de Informática na Escola. Campo Grande, MS, Brasil.

Copi, Irving M. 1978. Introdução à Lógica.2ºd.São Paulo : Mestre Jou.

IEEE Learning Technology Standards Committee (IEEE/LTSC). Final 1484.12.1-2002 LOM Draft Standard. Disponível em: http://ltsc.ieee.org/wg12.

Galotta, A. 2007. Objetos de aprendizagem. Disponível em: webmsbr.tv1.com.br/brasil/educacao/parceiro/

Piaget, Jean. 1975. Gênese das estruturas lógicas elementares. Rio de Janeiro: Forense.

Nunes, C. 2004. Desenvolvendo LOs. Disponível em: http://www.microsoft.com/brasil/educacao/parceiro.

Rauber, J; Rosseto, M; Fávero, A M; Fávero, A A; Tonieto, C. 2003. Que tal um pouco de lógica?!, Ed. Clio Livros, Passo Fundo.

Reategui, Eliseo B.; Moraes, Marcia C. 2006. Agentes pedagógicos animados: concepção, desenvolvimento e aplicação. XVII Simbósio Brasileiro de Informática na Educação - SBIE. UCB, Brasília, Brasil.

RIVED. 2007. Rede Internacional Virtual de Educação. Disponivel em: <rived.proinfo.mec.gov.br/ - 3k> Acesso em: 10 de maio de 2007.

Tarouco. Liane. 2004. Avaliações de Objetos de Aprendizagem. CINTED/UFRGS. Disponível em: http://penta2.ufrgs.br/edu/objetosaprendizagem/

Weis, A. M; Cruz, M. L. 2001. A Informática e os Problemas Escolares de Aprendizagem. Editora DP\&A. Rio de Janeiro. 